This is the pre-peer reviewed version of the following article: Barrena, R. et al. "Effect of inoculation dosing on the composting of source-selected organic fraction of municipal solid wastes" in Journal of chemical technology and biotechnology (Wiley), vol. 81, issue 3 (March 2006), p. 420-425, which has been published in final form at DOI 10.1002/jctb.1418. This article may be used for non-commercial purposes in accordance with Wiley Terms and Conditions for Self-Archiving."

\title{
Effect of inoculum dosing on the composting of source-selected organic fraction of municipal solid wastes
}

Raquel Barrena, Estel.la Pagans, Gary Faltys and Antoni Sánchez*

Escola Universitària Politècnica del Medi Ambient

Universitat Autònoma de Barcelona

Rbla Pompeu Fabra 1, 08100-Mollet del Vallès (Barcelona, Spain)

*Corresponding Author: Dr. Antoni Sánchez

Escola Universitària Politècnica del Medi Ambient

Universitat Autònoma de Barcelona

Rbla Pompeu Fabra 1, 08100-Mollet del Vallès (Barcelona, Spain)

Tel.: (34) 9357967 84; Fax: (34) 935796785

E-mail: asanchez@eupma.uab.es

Short title: Inoculation in composting of municipal solid wastes. 


\begin{abstract}
The effects of a commercial inoculum (MicroGest 10X, Brookside Agra L.C.) on the field-scale composting of source-selected organic fraction of municipal solid wastes (OFMSW) have been studied by following routine parameters of the composting process (temperature, oxygen content and moisture) and biologically-related tests such as the respirometric index and the maturity grade. The inoculum was added to composting piles of OFMSW at different levels: Control (no added inoculum), Treatment A (10 $\mathrm{CFU} / \mathrm{g}$ of OFMSW), Treatment B $\left(10^{6} \mathrm{CFU} / \mathrm{g}\right.$ of OFMSW $)$ and Treatment $\mathrm{C}\left(10^{7} \mathrm{CFU} / \mathrm{g}\right.$ of OFMSW). The inoculum selected produced a significant acceleration of the composting process with high levels of biological activity in the thermophilic phase. In terms of composting acceleration and economical costs the optimal treatment was B, which produced a reduction of approximately half of the total composting time. Treatment $\mathrm{C}$ did not improve significantly the results obtained with treatment $\mathrm{B}$, whereas treatment $\mathrm{A}$ has little effect on the OFMSW composting when compared to control experiment. Respirometric index (determined at $55^{\circ} \mathrm{C}$ ) and maturity grade appeared to be the most reliable tests to follow the biological activity of the OFMSW composting. On the other hand, routine parameters such as temperature, oxygen content and moisture showed no significant differences among the different inoculation levels tested in the composting process.
\end{abstract}

Key words: Biological Activity, Composting, Stability, Inoculation, Maturity, Municipal Solid Wastes. 


\section{Introduction}

In recent years, the international policy on management of organic wastes has been increasingly directed towards recycling. There are different technologies to recycle organic wastes from municipal solid wastes (mainly composed of kitchen wastes, pruning wastes and green wastes) and composting is often presented as a low-technology and lowinvestment process to convert organic wastes to an organic fertilizer known as compost.

Composting is a biotechnological process by which different microbial communities decompose organic matter into simpler nutrients. Composting is an aerobic process, which requires oxygen to stabilize the organic wastes, optimal moisture and porosity. ${ }^{1}$ Temperature, oxygen and moisture are often selected as the control variables in the composting process, because they can be simply determined. However, there is scarce information about the monitoring of biological activity of composting processes in comparison with other biotechnology fields. Probably, the parameters most commonly used to describe the biological activity of a composting process or compost are stability and maturity. Stability is related to the presence of easily biodegradable compounds and is routinely measured by the respirometric index as the Oxygen Uptake Rate (OUR) of a compost sample. ${ }^{2,3}$ Maturity is usually determined with self-heating tests in Dewar vessels ${ }^{4}$ or germination indices ${ }^{5}$, and it is used in relation to compost application and plant growth. ${ }^{6}$

As a biotechnological process, composting needs inoculation. Nevertheless, most of the traditionally composted wastes, such as source-selected organic fraction of municipal solid wastes (OFMSW), sewage sludge or animal manure, are supposed to contain enough autochthonous microorganisms and thus inoculation is rarely used in composting. In fact, opposite results on the inoculation of different composting processes can be found in 
literature. In general, from previous studies, it seems that when a specialized inoculum is used some positive effects can be observed. For instance, it has been reported that a bacterial inoculum enriched with feather-degrading bacteria enhances keratin degradation and biofilm formation in poultry compost, ${ }^{7}$ or that the biodegradability of poly-caprolactone in a compost environment is significantly altered by the type of inoculum used. ${ }^{8}$ However, other similar works have not found significant improvements when some inoculum was used in the composting of different wastes. The failure of inoculum in these works is attributed to different reasons, such as the presence of sufficient quantity of microorganisms in composted materials for an adequate composting ${ }^{9,10}$ or competition between autochthonous and inoculated strains. ${ }^{11}$ In other works, although there is no perceptible effect of inoculation, it is pointed that inoculation decreases the variability observed in the composting experiences. ${ }^{12}$

Nevertheless in most of the cited works only routine parameters of the composting process are profiled and compared between inoculated and non-inoculated treatments. Moreover, only an inoculum dosage is usually tested. In the few works when microbiological parameters are determined, it seems clear that inoculation can have a positive effect in the composting acceleration and the quality of the compost, especially in the first thermophilic stage of the process. ${ }^{13,14}$

The objective of this work is to study systematically the effect of different dosages of a commercial inoculum (MicroGest 10X, Brookside Agra L.C.) in the acceleration of the composting process of OFMSW. The study is focused on the biological activity of the OFMSW composting (measured as respirometric index and maturity grade), since this is the key parameter for the determination of an inoculum performance. 


\section{Materials and Methods}

Organic wastes

Source-selected organic fraction of municipal solid wastes (OFMSW) was used as main substrate for composting experiments. OFMSW was obtained and composted at the composting plant of Jorba (Barcelona, Spain). Plastic, metal, glass and other visible contaminants of the organic fraction were manually removed.

\section{Inoculum composition and preparation}

A commercial inoculum named MicroGest 10X was generously provided by Brookside Agra L.C. MicroGest 10X is a combination of enzymes and microorganisms. Its ingredients are: dried Bacillus megaterium fermentation product, dried Bacillus licheniformis fermentation product, dried Bacillus subtilis fermentation product, dried Saccharomyces cerevisiae fermentation product, dried Trichoderma reesei fermentation extract, dried Aspergillus niger fermentation extract, dried whey and silicon dioxide. The minimum number of total Bacillus bacteria is $4 \cdot 10^{9}$ Colony Forming Units (CFU)/g of MicroGest 10X.

The treatments applied to the OFMSW piles were: Control (no added inoculum), A $\left(10^{5} \mathrm{CFU} / \mathrm{g}\right.$ of OFMSW), B (10 ${ }^{6} \mathrm{CFU} / \mathrm{g}$ of OFMSW $)$ and $\mathrm{C}\left(10^{7} \mathrm{CFU} / \mathrm{g}\right.$ of OFMSW $)$. According to the different treatment applied, different weights of MicroGest 10X powder were suspended in $5 \mathrm{~L}$ of distilled water per ton of OFMSW at room temperature to reach the desired concentration of CFU/g of OFMSW. The amount of water was maintained constant in all the treatments to prevent a change in moisture content of OFMSW. This suspension is prepared fresh within one hour before the application and applied uniformly 
by spraying on the solid waste. All the composting material was turned after inoculation to spread the bacterial consortium.

\section{Composting experiments}

Piles of source-separated OFMSW were investigated. The piles were built according to the normal operation of the plant. Trapezoidal piles (base: $2 \mathrm{~m}$; height: $1.5 \mathrm{~m}$ ) of approximately $30 \mathrm{t}$ of OFMSW mixed with pruning wastes in a 2:1 volumetric ratio were used for each treatment of inoculum applied. Piles were turned weekly using a turner Backhus Model 15.50. No forced aeration was provided.

Pile temperature was measured at 50 and $100 \mathrm{~cm}$ depth and pile oxygen content was measured at 100 and $150 \mathrm{~cm}$ depth in 4 points of the pile. Temperature and oxygen values are presented as average values. Variability between temperature and oxygen values measured at different points of the pile was in the range of 10-20\% (error bars not included in figures due to space limitations). Temperature was measured with a portable Pt-100 sensor (Delta Ohm HD9214) and oxygen concentration in interstitial air was measured with a portable $\mathrm{O}_{2}$ detector (Oxy-ToxiRAE, RAE) connected to a portable aspiration pump. Other parameters of the composting process were analyzed in the laboratory after extracting a representative solid sample (approximately 2-L volume) of the pile from 4 different points. Samples were sieved in order to remove glass, plastics and other inert and oversize materials. For respirometric experiments, Rottegrade self-heating test and Solvita ${ }^{\circledR}$ test, moisture content was adjusted to a range of $40-50 \%$ if required. 
Respirometric tests

A static respirometer was built according to an original model previously described ${ }^{2}$ and following the modifications and recommendations given by the U.S. Department of Agriculture and U.S. Composting Council. ${ }^{15}$

Approximately $250 \mathrm{~mL}$ of compost samples (representative sample of the pile from 4 different locations) were placed in $500 \mathrm{~mL}$ Erlenmeyer flasks on a nylon mesh screen that allowed air movement under and through the solid samples. The setup included a water bath to maintain the selected temperature during the respirometric test. In the experiments presented, respirometric tests were obtained at two temperatures: $55^{\circ} \mathrm{C}$ (related to the actual biological activity of the process) and $37^{\circ} \mathrm{C}$ (related to the stability of the material). Prior to the assays, samples were incubated for 18 hours at $37^{\circ} \mathrm{C}$ or 4 hours at $55^{\circ} \mathrm{C}$. During all the incubation period samples were aerated with previously humidified air at the sample temperature. The drop of oxygen content in a flask containing a compost sample was monitored with a dissolved oxygen meter (Lutron 5510, Lutron Co. Ltd., Taiwan) connected to a data logger. The rate of respiration of the compost sample (Oxygen Uptake Rate, OUR, based on total organic matter content, TOM) was then calculated from the slope of oxygen level decrease according to the standard procedures. ${ }^{15}$ Results of the static respirometric index referred to total organic matter content are presented as an average of three replicates. The standard deviation between respirometric replications is in the range of $5-10 \%$ (error bars not included in figures due to space limitations). 


\section{Analytical Methods}

Moisture, total organic matter (TOM), pH, electrical conductivity (EC), Solvita test and Rottegrade self-heating test were determined according to the standard procedures. ${ }^{15}$ Solvita test is based on the qualitative calculation of $\mathrm{CO}_{2}$ and $\mathrm{NH}_{3}$ emissions which are correlated to a maturity grade, with a range from 1 (raw material) to 5 or 8 for $\mathrm{NH}_{3}$ or $\mathrm{CO}_{2}$ respectively (finished compost). The Rottegrade self-heating test measures a temperature rise due to the exothermic biological and chemical activity with a range from I (fresh material) to $\mathrm{V}$ (compost completely mature). Representative samples of the pile from 4 different locations were used to carry out all the analytical tests.

\section{Data analysis}

Variance analysis was done to compare mean values of different parameters studied for each treatment applied using the least-significance difference test at 5\% level of probability.

\section{Results and Discussion}

Evolution of composting experiments

Different routine parameters were determined in the composting experiments. Figure 1 presents the temperature profiles obtained for the different experiments (average values). Thermophilic range of temperatures $\left(>50^{\circ} \mathrm{C}\right)$ could be easily reached for all the dosages of inoculum, including the control experiment. According to Figure 1, temperaturetime profiles indicated that the material should be hygienized. However, no significant differences $(\mathrm{P} \leq 0.05)$ were observed among the treatments used. 
Figure 2 shows the evolution of interstitial oxygen content of the material for each treatment. Although the oxygen profiles were similar and differences among average oxygen values were not statistically significant $(\mathrm{P} \geq 0.05)$, it seemed that dose $\mathrm{C}$ of inoculum implied lower oxygen concentrations in some samples. Nevertheless, all experiments showed an oxygen profile very similar to those found in typical windrow composting, ${ }^{1}$ with oxygen limitation in the first stage (some oxygen values below 5\%) and a final stage with high concentrations of oxygen (corresponding to a decrease in biological activity).

On the other hand, moisture quickly decreased for all the dosages (data not shown) according to the high temperatures reached, and water addition was necessary after 20-30 days of composting to maintain a moisture level over $40 \%$. No significant differences were detected for each treatment $(\mathrm{P} \geq 0.05)$. In conclusion, it can be stated that there were no significant differences among the treatments using different doses of inoculum in relation to the common composting parameters, such as temperature, oxygen content and moisture. The profiles obtained for these parameters were very similar to those found in typical windrow composting of OFMSW.

\section{Physico-chemical characteristics}

Moisture, TOM, EC and $\mathrm{pH}$ were determined for the initial sample of OFMSW and the final compost obtained for each treatment (after 100 days of composting). Results obtained are presented in Table 1. As can be seen in Table 1, only slight differences were observed among the treatments applied. In fact, this variability is usually observed in different batches of standard non-inoculated batches of OFMSW composting ${ }^{12,16}$ and they 
were not statistically significant. Therefore, it could be concluded that inoculation did not have a significant impact on these parameters.

\section{Biological activity indices}

Different measures of biological activity related to maturity and stability were used to follow the material evolution and include respirometric index (measured at $37^{\circ} \mathrm{C}$ and $55^{\circ} \mathrm{C}$ ), Rottegrade self-heating test and Solvita test. These tests have been extensively used in the composting field to characterize the stability and maturity of compost. ${ }^{2,4,17}$ However, the information they provide are qualitatively different. Thus, respirometry refers to the aerobic biological activity of the material, and it is recommended to monitor the composting process. ${ }^{18,19}$ Also, it can be determined at two different temperatures: $55^{\circ} \mathrm{C}$ (which is a measure of the real activity of the process in the thermophilic range) or $37^{\circ} \mathrm{C}$ (which is related to the stability of the material). It is generally considered that values of respirometric index (measured at $37^{\circ} \mathrm{C}$ ) below $1 \mathrm{mg} \mathrm{O} \mathrm{O}_{2} \cdot \mathrm{g} \mathrm{TOM}^{-1} \cdot \mathrm{h}^{-1}$ correspond to stable compost. $^{20}$ On the other hand, Rottegrade self-heating test and Solvita tests give information in form of maturity grade. In Europe, the Rottegrade self-heating test is commonly used to quantify the maturation of compost, with a range from I to $\mathrm{V}^{15}$ The results of the respirometric index (at $37^{\circ} \mathrm{C}$ and $55^{\circ} \mathrm{C}$ ) and maturity grade obtained for each treatment are presented in Figures 3, 4 and 5, respectively.

From Figures 3 and 4, it was obvious that doses B and C of inoculum produced a faster decrease of the respirometric index (measured at $37^{\circ} \mathrm{C}$ and $55^{\circ} \mathrm{C}$ ) than those observed for dose A and control, indicating a clear acceleration of the whole process. This fact can be due to a high microbial activity in the composting thermophilic phase, which finally 
produced a more stable product. As expected, it was also clear that between doses B and C, dose $\mathrm{C}$ is more effective. It can be concluded that larger quantities of inoculum accelerates the composting of OFMSW, however, the differences in the respirometric index between doses B and C probably are not high enough from the economical point of view. Finally, dose A does not seem to have a significant effect on the respirometric index. Thus, it seems that the main reason of the positive results obtained with MicroGest $10 \mathrm{X}$ is due to the fact that there is an increase in the number of active microorganisms that accelerates the degradation of organic matter. This is clearly observed from the values of respirometric index (Figure 4), which is directly related to the oxygen consumption of the aerobic microbial populations. ${ }^{21}$

As expected, when respirometric indices were determined at $37^{\circ} \mathrm{C}$ and $55^{\circ} \mathrm{C}$, differences between both indices were more important in the first thermophilic phase than in the final maturation phase, when the temperature was close to $37^{\circ} \mathrm{C}$. In fact, respirometric indices determined at $37^{\circ} \mathrm{C}$ were not statistically different $(\mathrm{P} \geq 0.05)$ from those determined at $55^{\circ} \mathrm{C}$ from day 50 on (corresponding to mesophilic phase, Figure 1). From 0 to 50 days (thermophilic phase of composting) the thermophilic microorganisms only exhibited a limited growth at $37^{\circ} \mathrm{C}$, whereas the mesophilic population was scarce. At $55^{\circ} \mathrm{C}$, the respirometric index was determined under thermophilic conditions and the microbial populations present in the material were fully active, resulting in high values of the respirometric index. In conclusion, it can be stated that the respirometric index can be used for monitoring the biological activity of the composting process; however, it should be determined at thermophilic conditions, whereas determinations at mesophilic temperature should be exclusively used for compost material in the maturation stage. The use of 
respirometric index as a measure of biological activity is of special relevance at full-scale facilities (specially in the maturation stage) where temperature is maintained in the termophilic range because of the limited heat transfer of the compost material (low thermal conductivity), the oxygen content is very close to that of ambient air and the moisture content is roughly constant. Therefore, in these situations the respirometric index provides a more accurate measure of the biological activity of the compost material.

On the other hand, results from Figure 5 (maturity grade) are very interesting because they confirm the results obtained for the respirometric index. Thus, it took 56 days for the control experiment to reach a maturity grade considered stable (IV), which is a typical time in the windrow composting of OFMSW in Spain. ${ }^{22}$ In the inoculated experiments, the acceleration in the process to obtain mature compost was spectacular. With dose B, it only took 28 days to obtain grade IV compost, and 49 days to obtain grade $\mathrm{V}$ (the maximum maturity grade). With dose A, the results were less positive, but better than control experiment. The results for dose $\mathrm{C}$ were similar to those obtained in experiment $\mathrm{B}$, which indicated that the optimal dose in terms of acceleration and cost was dose B. The optimal treatment in terms of maturity grade is therefore dose B, which produced a reduction of the $50 \%$ of the composting time.

Finally, Solvita test was studied for initial and final samples of compost (Table 1). From our results, there were no differences among the treatments using the Solvita test, and all the materials appeared to be only partially stabilized. These results were contradictory with respirometric index and maturity grade. It is probable that this test is not suitable to assess the stability of heterogeneous materials such as OFMSW, although it has been successfully used with other wastes in the final maturation stage. ${ }^{17}$ 


\section{Conclusions}

From the results obtained, it can be concluded that:

1) MicroGest 10X is an effective inoculum to accelerate the composting of OFMSW, by enhancing the biological activity in the thermophilic stage of the process.

2) Among the inoculum dosages tested, treatment $\mathrm{B}\left(10^{6} \mathrm{CFU} / \mathrm{g}\right.$ of OFMSW $)$ is the optimal in terms of reduction of the composting time (approximately 50\% reduction) and economics of the treatment. Treatment $\mathrm{C}$ (10-fold more inoculum amount than treatment B) does not improve significantly the composting of OFMSW in comparison to treatment B, whereas treatment A (10-fold less inoculum amount than treatment B) has little effect when compared to control experiment. The determination of an optimal dosage of inoculum appears to be as important as the decision to use it.

3) Routine parameters (temperature, oxygen content and moisture) are not statistically different among the treatments studied. However, temperature is a crucial parameter to study some aspects of the composting process such as compost sanitation or moisture control.

4) Parameters related with biological activity of the material such as stability and maturity are specially indicated to study the effects of inoculation of composting materials. Specifically, respirometric index (determined at $55^{\circ} \mathrm{C}$ ) and maturity grade can be considered as reference parameters in the composting field. Additionally, the use of respiration indices is recommended by the European Commission as the most suitable measure to certificate compost stability prior to its application to soil. ${ }^{23}$ 
5) Future work on the use of inoculating microorganisms in the composting process should be focused on the study of its effects on other types of organic wastes and composting plants configurations.

\section{Acknowledgments}

The authors wish to thank the financial support provided by the Spanish Ministerio de Ciencia y Tecnología (Project REN2003-00823). 


\section{References}

1. Haug RT, The Practical Handbook of Compost Engineering. Lewis Publishers, Boca Raton (1993).

2. Iannotti DA, Pang T, Toth BL, Elwell DL, Keener HM and Hoitink HAJ, A quantitative respirometric method for monitoring compost stability. Compost Sci Util 1:52-65 (1993).

3. Chica A, Mohedo JJ, Martín MA and Martín A, Determination of the stability of MSW compost using a respirometric technique. Compost Sci Util 11:169-175 (2003).

4. Weppen P, Determining compost maturity: evaluation of analytical properties. Compost Sci Util 10:6-15 (2002).

5. Bernal MP, Paredes C, Sánchez-Monedero MA and Cegarra J, Maturity and stability parameters of composts prepared with a wide range of organic wastes. Bioresource Technol 63:91-99 (1998).

6. Cooperband LR, Stone AG, Fryda MR and Ravet JL, Relating compost measures of stability and maturity to plant growth. Compost Sci Util 11:113-124 (2003).

7. Ichida JM, Krizova L, LeFevre CA, Keener HM, Elwell DL and Burtt EH. Bacterial inoculum enhances keratin degradation and biofilm formation in poultry compost. $J$ Microbiol Meth 47:199-208 (2001).

8. Ohtaki A, Akakura N and Nakasaki, K. Effects of temperature and inoculum on the degradability of poly-caprolactone during composting. Polym Degrad Stabil 62:279284 (1998). 
9. Faure D and Deschamps AM, The effect of bacterial inoculation on the initiation of composting of grape pulps. Bioresource Technol 37:235-238 (1991).

10. Nakasaki K, Watanabe A, Kitano $M$ and Kubota $H$, Effect of seeding on thermophilic composting of tofu refuse. J Environ Qual 21:714-719 (1992).

11. Baheri $\mathrm{H}$ and Meysami P, Feasibility of fungi bioaugmentation in composting a flare pit soil. J Hazard Mater B89:279-286 (2002).

12. Schloss PD and Walker LP, Measurement of process performance and variability in inoculated composting reactors using ANOVA and power analysis. Process Biochem 35:931-942 (2000).

13. Tiquia SM, Tam NFY and Hodgkiss IJ, Effects of bacterial inoculum and moisture adjustment on composting pig manure. Environ Pollut 96:161-171 (1997).

14. Bolta SV, Mihelic R, Lobnik F and Lestan D, Microbial community structure during composting with and without mass inocula. Compost Sci Util 11:6-15 (2003).

15. U.S. Department of Agriculture and U.S. Composting Council, Test methods for the examination of composting and compost. Edaphos International, Houston (2001).

16. Schloss PD, Chaves B and Walker LP, The use of the analysis of variance to assess the influence of mixing during composting. Process Biochem 35:675-684 (2000).

17. Changa CM, Wang P, Watson ME, Hoitink HAJ and Michel FC, Assessment of the reliability of a commercial maturity test kit for composted manures. Compost Sci Util 11:125-143 (2003).

18. Mari I, Ehaliotis C, Kotsou M, Balis C and Georgakakis D, Respiration profiles in monitoring the composting of by-products from the olive oil agro-industry. Bioresource Technol 87:331-336 (2003). 
19. Liang C, Das KC and McClendon RW, The influence of temperature and moisture contents regimes on the aerobic microbial activity of a biosolids composting blend. Bioresource Technol 86:131-137 (2003).

20. California Compost Quality Council, CCQC-Compost Maturity Index. http://www.crra.com/ccqc/ccqchome.htm (2001).

21. Gea MT, Barrena R, Artola A and Sánchez A, Monitoring the Biological Activity of the Composting Process: Oxygen Uptake Rate (OUR), Respirometric Index (RI) and Respiratory Quotient (RQ). Biotechnol Bioeng 88:520-527 (2004).

22. Barrios S, Fernández R, Vázquez F and Font X, Composting Activity in Catalonia. Biocycle 45:64-66 (2004).

23. European Commission. Working document. Biological treatment of biowaste. 2nd draft. URL: http://europa.eu.int/comm/environtment/waste/facts_en.htm (2001). 
Tables

Table 1: Initial characteristics of OFMSW composted and final characteristics of the compost obtained for each treatment studied.

\begin{tabular}{|l|c|c|c|c|c|}
\hline Parameter & Initial & Control & Treatment A & Treatment B & Treatment C \\
\hline Moisture (\%) & 57.98 & 35.5 & 35.2 & 33.1 & $24.2^{*}$ \\
\hline TOM (\%) & 62.86 & 45.8 & 47.7 & 44.4 & 46.8 \\
\hline $\mathrm{pH}$ & 6.90 & 8.60 & 8.33 & 8.48 & 8.90 \\
\hline EC $\left(\mathrm{mS} \mathrm{cm}^{-1}\right)$ & 2.97 & 5.25 & 4.92 & 5.57 & 4.82 \\
\hline Solvita $\mathrm{CO}_{2}$ & 3 & 5 & 5 & 5 & 5 \\
\hline Solvita $\mathrm{NH}_{3}$ & 4 & 5 & 4 & 4 & 4 \\
\hline
\end{tabular}

*Statistically different $(\mathrm{P}<0.05)$. 


\section{Figure Legends}

Figure 1: Temperature profiles (average values) for the treatments studied. Legend is included in the graphic.

Figure 2: Oxygen content profiles (average values) for the treatments studied. Legend is included in the graphic.

Figure 3: Respirometric index $\left(37^{\circ} \mathrm{C}\right)$ profiles for the treatments studied. Legend is included in the graphic.

Figure 4: Respirometric index $\left(55^{\circ} \mathrm{C}\right)$ profiles for the treatments studied. Legend is included in the graphic.

Figure 5: Maturity grade profiles for the treatments studied. Legend is included in the graphic. 
Figure 1: Barrena et al.

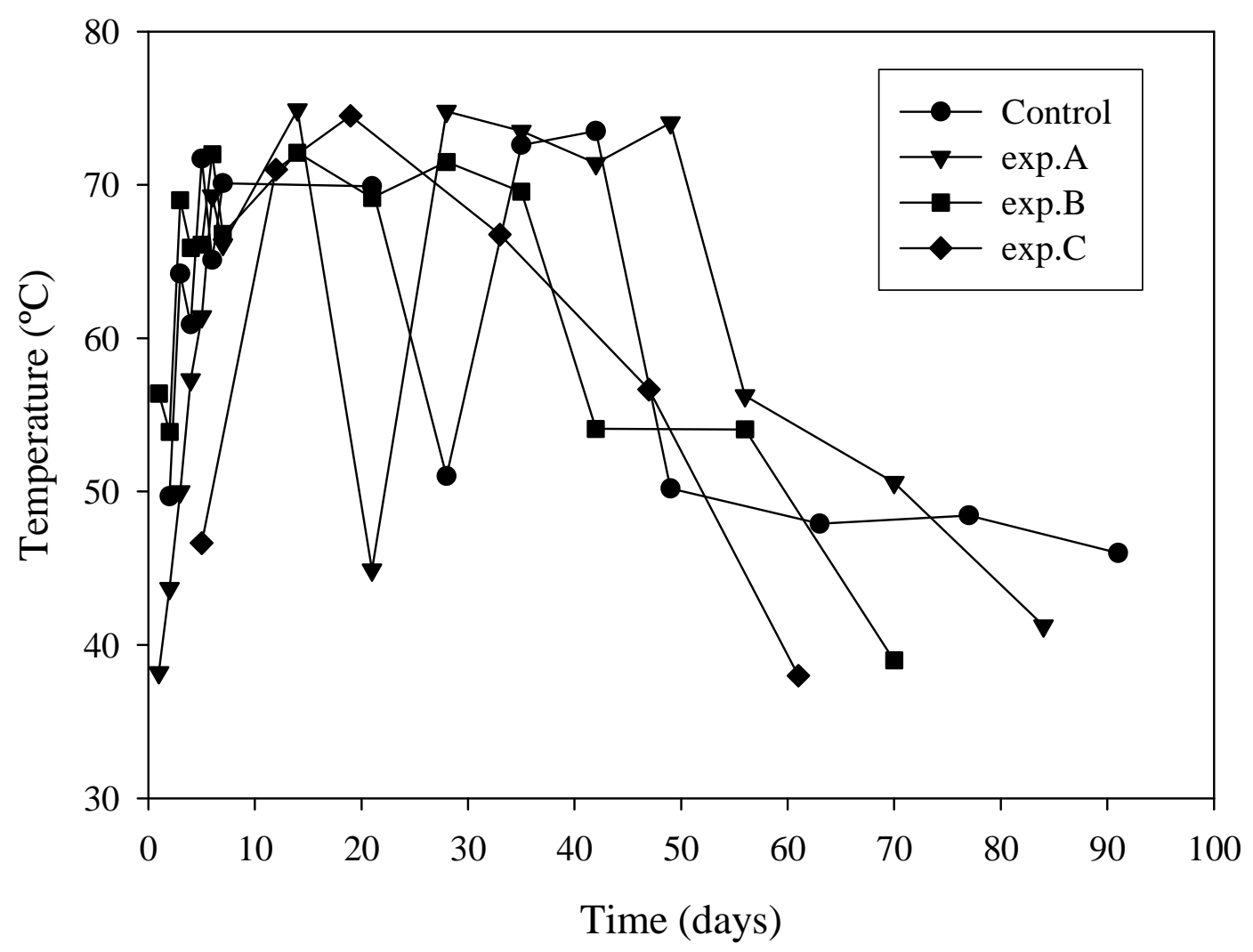


Figure 2: Barrena et al.

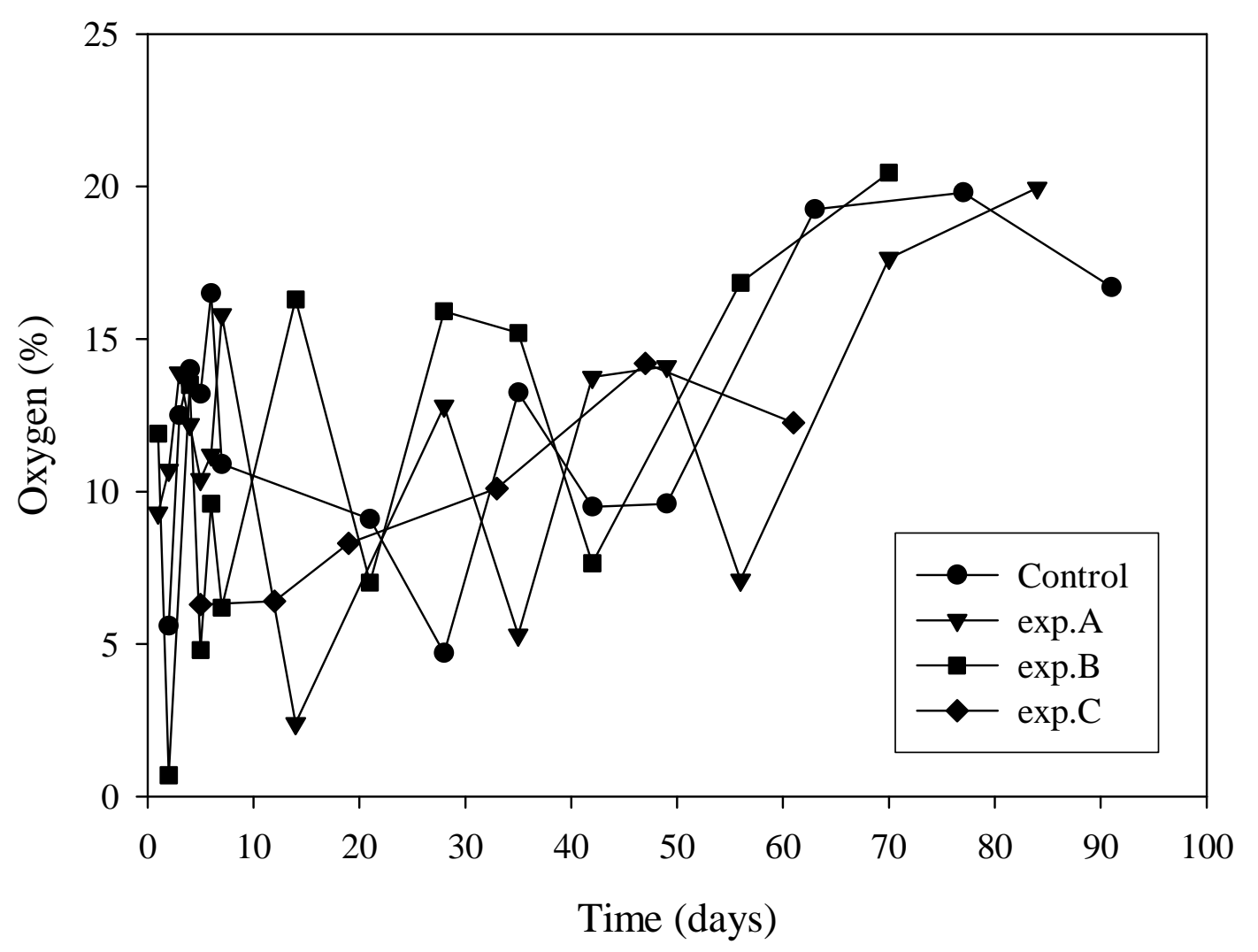


Figure 3: Barrena et al.

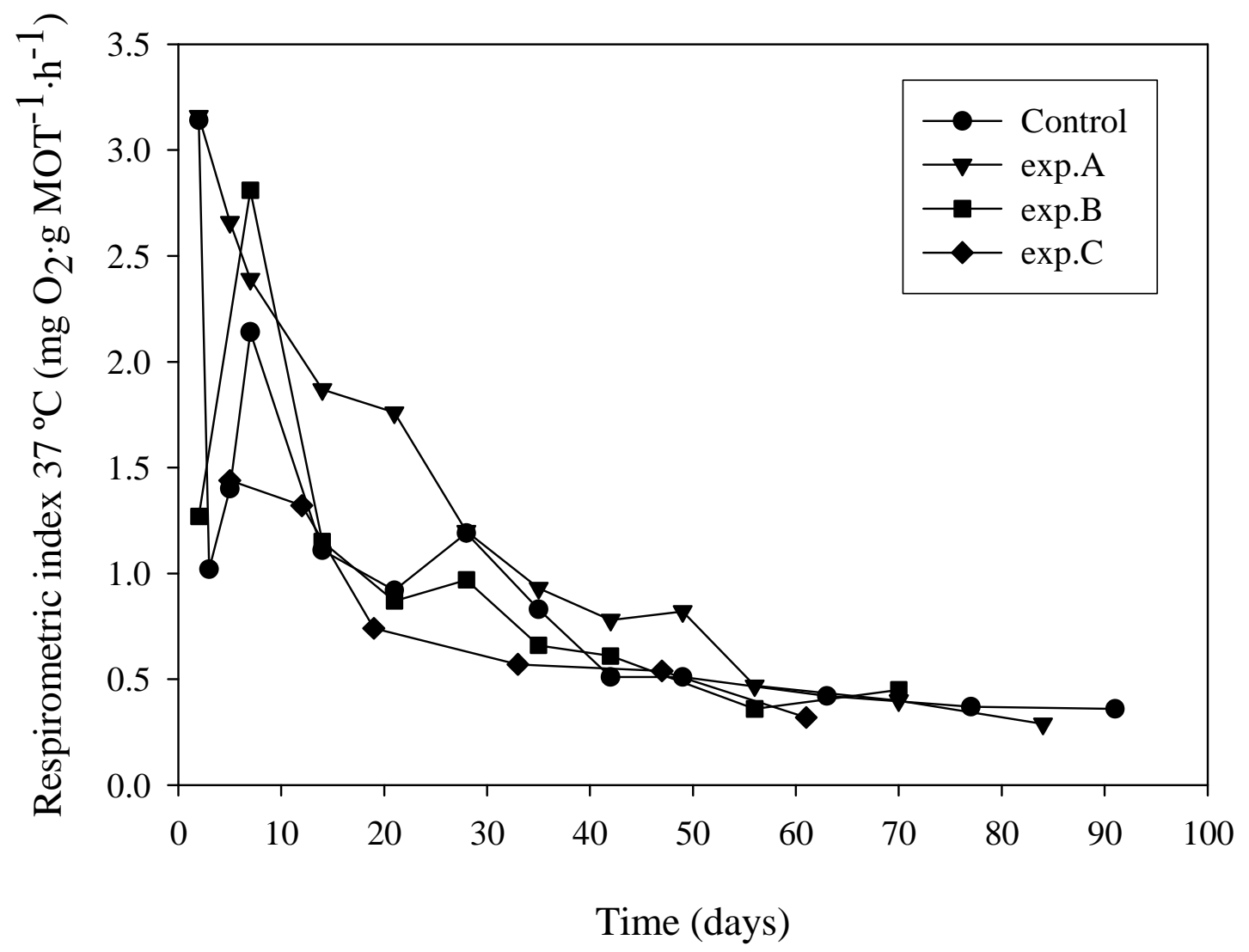


Figure 4: Barrena et al.

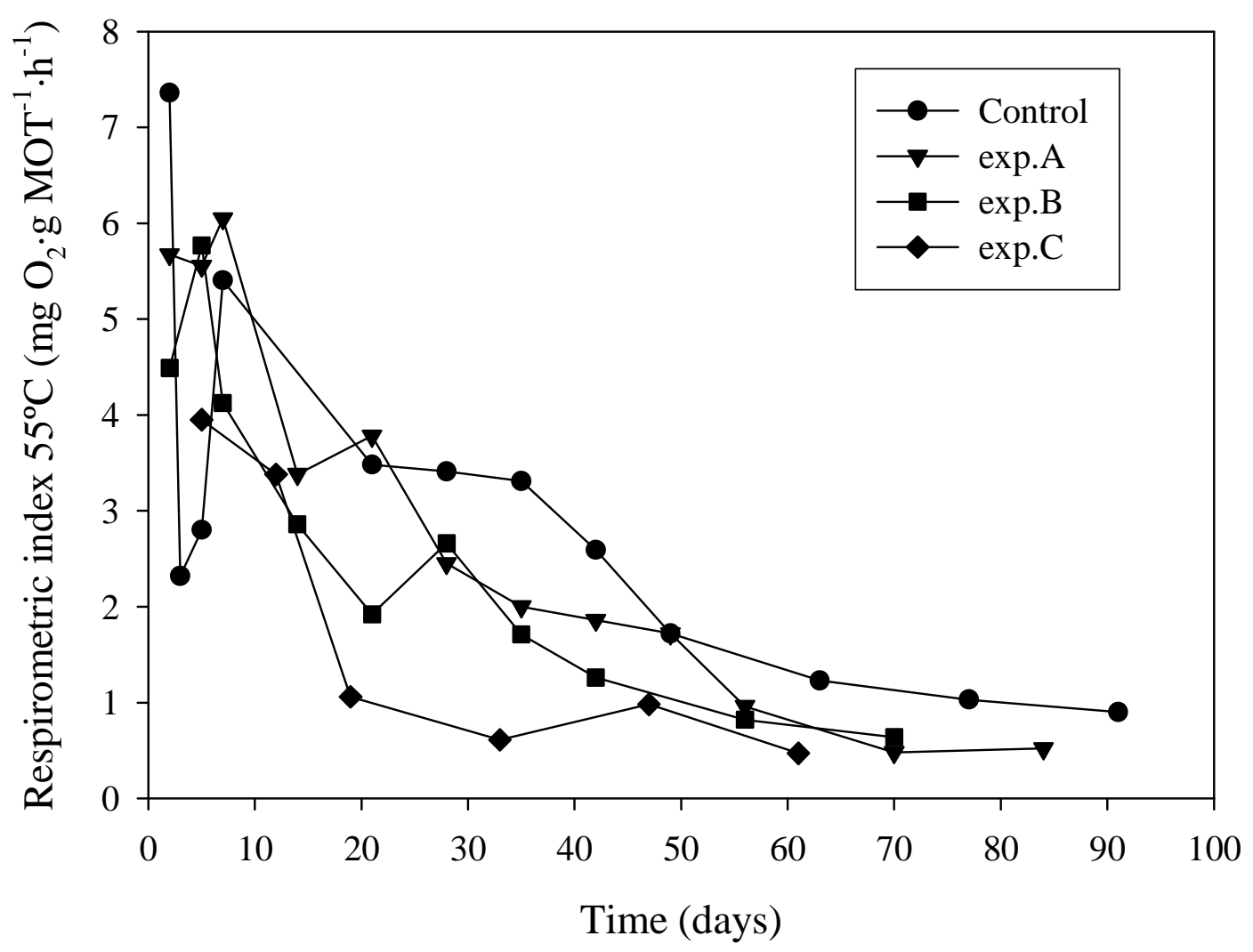


Figure 5: Barrena et al.

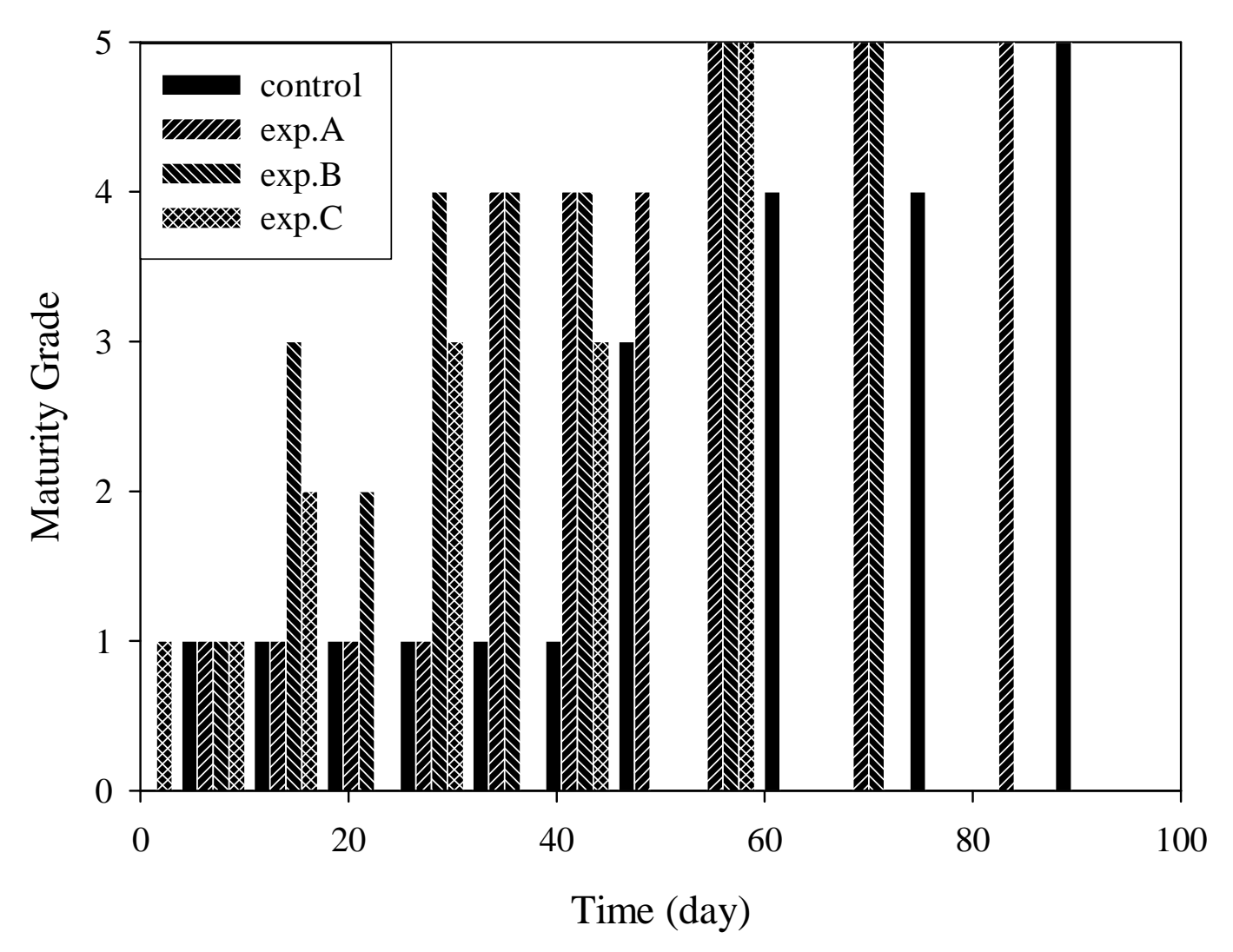

